Check for updates

Cite this: J. Anal. At. Spectrom., 2020, 35,1199

Received 10th February 2020

Accepted 15th May 2020

DOI: $10.1039 / \mathrm{d} 0 \mathrm{ja} 00045 \mathrm{k}$

rsc.li/jaas

\title{
Mineralisation within human tooth cementum identified by secondary ion mass spectrometry $\uparrow$
}

\author{
Marija Edinborough, (D)*a Matthew Pilgrim, bc Sarah Fearn, ${ }^{\text {d }}$ Andrijana Cvetković, \\ Branko Mihailović, , Rade Grbiće and Kevan Edinborough (iD *a
}

\begin{abstract}
Life-history parameters such as pregnancies, skeletal trauma, and renal disease have previously been identified from hypomineralised growth layers (incremental lines) of acellular extrinsic fibre cementum (AEFC) using optical microscopy. We show that the precise periodicity of these growth layers remains poorly understood, so life history parameters for putative cementum deposition periodicity cannot be rigorously calculated. In an attempt to better understand the underlying formation processes, our study investigates whether or not mineralisation of AEFC incremental lines clearly indicate life history parameters in an ideal sample, using light microscopy, electron microscopy, and Time-of-Flight Secondary Ion Mass Spectrometry (ToF-SIMS). Based on our results we reject the possibility of accurate estimation of the distribution of mineralisation of tooth cementum using light and scanning electron microscopy alone. On the other hand, we detect an apparent drop in calcium in the AEFC of a patient with six documented full-term pregnancies, using ToF SIMS. We conclude that although ToF-SIMS analysis holds great promise for increasing our knowledge of cementum composition, far more caution is required by researchers linking observed lines in this tissue to underlying causal life history mechanisms and explanations.
\end{abstract}

\section{Introduction}

Acellular extrinsic fibre cementum (AEFC) is deposited in a regular annual rhythm around the cervical two thirds of human tooth roots, with varying degrees of mineralisation..$^{1,2}$ Annual growth of AEFC results in alternating dark and light band called an incremental line. By counting number of incremental lines and adding it to the year of the eruption of the tooth observed one can estimate chronological individual age. $^{3-5}$ It has been also reported that certain life-history parameters (LHP), such as pregnancies, skeletal trauma, and renal disease, can be identified and precisely datable from incremental lines of AEFC in human teeth by observing their visual effects, using refined preparation techniques in combination with digital micrographs. ${ }^{3}$ These life history parameters

${ }^{a}$ Melbourne Dental School, The University of Melbourne, 720 Swanston St., Melbourne, Victoria, Australia. E-mail: marija.edinborough@unimelb.edu.au; kevan. edinborough@unimelb.edu.au

${ }^{b}$ Eastman Dental Institute, University College London, 256 Grays Inn Rd, London WC1X $8 L D, U K$

${ }^{c}$ Centre for Experimental Medicine, Queen's University Belfast, 97 Lisburn Rd, Belfast BT9 $7 B L, U K$

${ }^{d}$ Royal School of Mines, Department of Materials, Imperial College London, Exhibition Road, London, SW7 2AZ, UK

${ }^{e}$ Faculty of Medicine, University of Priština, Anri Dinana b.b., Kosovska Mitrovica, Serbia

$\dagger$ Electronic supplementary information (ESI) available. See DOI: 10.1039/d0ja00045k putatively appear to change calcium metabolism, ${ }^{6,7}$ assuming a related lack of available calcium at the mineralisation front of the cementum causes formation of a visually different incremental AEFC line. ${ }^{3}$ In a study on humans, ${ }^{3}$ as well as in great apes $^{8}$ "suspicious" AEFC lines were successfully detected as being visibly broader and translucent in tooth ground sections (70-80 $\mu \mathrm{m}$ thick) under optical magnification with transmuted polarized light. These studies also showed that some of the LHPs affecting mineralisation of AEFC are precisely datable from the AEFC cross-sections. On the other hand, in a controlled study undertaken on goats, Lieberman ${ }^{2}$ showed that AEFC bands corresponding to a control diet low in minerals including calcium and phosphorus appeared to be opaquer and relatively narrower, as observed from X-ray microradiographs of thin ground sections (50 $\mu \mathrm{m}$ thick). Lieberman described these bands as hypermineralised (denser) due to reduced cementogenesis. Separately, a study undertaken by Cool and colleagues ${ }^{9}$ reported that cementum growth layers are not the result of changes in mineral density at all, as they failed to detect cementum growth layers using scanning electron microscope (SEM) equipped with backscattered electrons detector (BSE). The most recent study on composition and structure of AEFC, using Raman imaging analysis ${ }^{10}$ argues that darker bends in AEFC lines correspond to higher mineral/ organic ratio when compared to brighter lines.

Due to the regular annual rhythm in their layering, AEFC incremental lines are more frequently used as a chronological 
age estimation aid than for the LHPs reconstruction. This relatively frequent use of AEFC growth patterns in individual age estimation ${ }^{11-22}$ is carefully qualified or subsequently disputed. ${ }^{23-25}$ Continued caution is required, as cementum is the least known of all the human mineralised tissues ${ }^{\mathbf{1}}$ and lacks rigorously controlled human clinical studies. Apart from a couple of the examples, ${ }^{3,15}$ clinical studies have rarely been used to support these pioneering cause-effect claims. As such, life history researchers cannot entirely rely on the results of these studies alone, which clearly require more extraordinary supporting evidence. Furthermore, cementum research is considerably hampered by an over-emphasis on (more economical) optical microscopy as summarised by Naji and colleagues. ${ }^{5}$ The optical appearance of cementum incremental lines is not fully understood yet, let alone the underlying complex mineralisation process(es). Whilst these authors are clearly aware of the limitations in cementum research, progress continues at a glacial pace. Worse still, some authors recently claimed to have unequivocally discovered evidence for human pregnancies in tooth cementum tissue ${ }^{26}$ and fail to provide independent instrumental support or any other critical testing protocols.

Here we adopt a far more focused and sceptical approach to life history parameter research, to investigate if the degree and distribution of mineralisation of AEFC incremental lines varies at all throughout the cementum with an ideal human case study tooth sample, and if so, can it be employed in detection of one significant LHP therein, namely a full-term pregnancy. To do so, we employ a comparative approach towards the study of AEFC incremental lines. We compared visual effects and direct elemental microanalysis of the degree and distribution of mineralisation of AEFC from a patient with a known life history of six full term pregnancies, using light and Scanning Electron Microscopy (SEM) with Energy Dispersive X-ray Analysis (EDS), and Time-of-Flight Secondary Ion Mass Spectroscopy (ToFSIMS).

\section{Material and methods}

A mandibular canine was extracted from a Caucasian woman undergoing necessary dental intervention at the University Hospital Kosovska Mitrovica. The informed consent to use the tooth for this research was obtained from the patient as well as her anamnestic data (Table 1). The patient was born and raised in the region of Kosovska Mitrovica. At the time of the extraction she was 66 years old with no previous history of renal disease, endocrinal problems, skeletal fractures or trauma. The patient reported six verified pregnancies that carried to full-term, starting at the age of 19 with the last one at age of 31 (Table 1). Thus,

Table 1 The patient's anamnestic data

Tooth extracted: 43 (left mandibular canine)

Sex: female

Age at the extraction: 66 years

Tooth eruption age: 9.6 years

$\begin{array}{lllllll}\text { Age at pregnancies: } & 19 & 21 & 25 & 27 & 30 & 31\end{array}$ samples from this patient provide an ideal opportunity to crosscheck any resultant pregnancy-cementum mineralisation relationship using multiple methods, not just optical microscopy. After the extraction, the tooth was placed in a labelled vial containing physiological saline (solution of $0.90 \% \mathrm{w} / \mathrm{v}$ of $\mathrm{NaCl}$ ). The tooth was free from obvious signs of pathology.

\section{Transmitted polarized light microscopy analysis}

Prior to sectioning, the tooth was sterilized by being placed in a vial, containing $10 \mathrm{ml}$ of ethanol (70\%), for two days. The tooth was then air-dried and completely submerged in epoxy resin (compared to the protocol of making a resin mixture: $1 \mathrm{l}$ of SpeciFix resin corresponds to $\mathrm{ml} 200 \mathrm{ml}$ SpeciFix-20 Curing Agent). A transverse cross section, $80 \mu$ thick, was taken from the mid-root third of the tooth using a saw microtome (Leitz 1600 , Germany), and mounted on glass slide. Section thickness was measured with a micrometer screw-gauge (Mitutoyo Series 116, Japan). The section was examined using transmitted polarized light microscope (Leica DM5500). Visibility and visual effects of cementum growth layers were observed on 10 digital photos. Incremental lines on each photograph were counted by three observers, three times each (Table 2).

\section{Scanning electron microscopy (SEM) with energy dispersive X- ray analysis (EDS) for measurement of elements}

The resin block with exposed mid-root surface represented the sample to be analysed by SEM-EDS was coated with carbon (Quorum K975x carbon coater; Quorum Technologies, UK). The prepared sample was examined at $20 \mathrm{keV}$ by scanning electron microscopy using a Philips XL30 E-SEM (Hillsboro, OR, USA) equipped with an Oxford instruments energy dispersive X-ray analysis detector using Oxford Instruments INCA software. The EDS analysis was employed to determine whether there are mineral component compositional changes between cementum growth layers. EDS analysis was performed on the same sections employed for SIMS imaging. Beam positioning was achieved by viewing the BSE image at $500 \times$ magnification.

Line scans of cementum growth layers were subject to an acquisition time of $100 \mathrm{~s}$ (working distance $10 \mathrm{~mm}$, take-off angle $35^{\circ}$ ) to obtain X-ray spectra. The X-ray spectra were used to determine which minerals were present and the $\mathrm{Ca} / \mathrm{P}$ atomic percent ratio.

\section{Identification of Ca and hydroxyapatite (HAp) by time of flight-secondary ion mass spectrometry imaging}

The sample preparation for ToF-SIMS imaging comprised several steps and it was performed at University College

Table 2 Results of the reported counts of incremental lines from the tooth cross-section

\begin{tabular}{llllll}
\hline & Mean & Median & Maximum & Minimum & Mode \\
\hline Observer 1 & 36.6 & 38.5 & 44 & 34 & 34 \\
Observer 2 & 47.3 & 49 & 54 & 39 & 50 \\
Observer 3 & 22.7 & 22 & 27 & 19 & 20,22
\end{tabular}


London, Institute of Archaeology. The procedure was tailor made for this research, namely the identification of Ca and HAp form AEFC growth layers using ToF-SIMS. After the cross section was cut out from the mid-root of the patient's tooth, the exposed root surface mounted in the resin was the sample analysed using ToF-SIMS. The following preparation step was polishing, undertaken using a rotating wheel and polishing media. This step is required to remove the surface damage that occurred during sectioning and to provide a flat surface. The polishing procedure included the use of a series of progressively finer polishing pads and diamond compounds, from $2-1 / 4 \mu$ (Kemet Diamond paste). The final step was ultrasonic cleaning (1 $\mathrm{min}$ at $40 \mathrm{kHz}$ ) using deionized water. This step was performed in order to thoroughly remove all traces of contamination tightly adhering or embedded onto the sample surface.

Secondary ion mass spectrometry and secondary ion mapping was performed using a TOF.SIMS5 mass spectrometer (ION-TOF, Münster, Germany), at the Imperial College London. Micrometre resolution was used for secondary ion mapping within $m / z 0-880$. The system is comprised of a bismuth primary ion beam, operating at $25 \mathrm{keV}$ and tuned to use the $\mathrm{Bi}_{3}{ }^{+}$ cluster for greater secondary ion yield, and a low energy electron flood gun for charge compensation. The choice of using $\mathrm{Bi}_{3}{ }^{+}(25$ $\mathrm{keV}$ ) instead of $\mathrm{Bi}^{++}(50 \mathrm{keV})$ was made to minimize fragmentation of the obtained signals. Greater secondary ion yield increases the detection sensitivity and reduces the matrix effect in ToF-SIMS. ${ }^{27}$ Cluster ion sources, such as $\mathrm{Bi}_{3}$, are used to identify larger HAp fragment ions at for example $\mathrm{m} / \mathrm{z} 485,541$, 597, and 653, identified as $\mathrm{Ca}_{5} \mathrm{P}_{3} \mathrm{O}_{12}{ }^{+}, \mathrm{Ca}_{6} \mathrm{P}_{3} \mathrm{O}_{13}{ }^{+}, \mathrm{Ca}_{7} \mathrm{P}_{3} \mathrm{O}_{14}{ }^{+}$, and $\mathrm{Ca}_{8} \mathrm{P}_{3} \mathrm{O}_{15}{ }^{+}$, respectively. Ionic species sputtered from the surface under the bismuth bombardment are steered into a reflectron time-of-flight mass analyzer. Before mass spectrometry was performed, an $\mathrm{Ar}_{n}{ }^{+}$cluster ion beam was used to remove any surface organic contaminants, and to reduce matrix effect when investigating the composition of tooth sections. ${ }^{28}$ Identified peaks strongly localized to cementum growth layers were mapped on single ion maps. Positive-ion spectra were acquired from two different $100 \times 100 \mu \mathrm{m}$ regions of tooth encompassing the entire AEFC width from mesio-buccal and disto-buccal side of the tooth, respectively to localize of HAp and identification of different $\mathrm{Ca} / \mathrm{P}$ phases within cementum layers. Data sets were analysed using SurfaceLab 6 (IONTOF, Muenster, Germany). The AEFC sections images were normalized to the respective total ion images to account for the instrument conditions change. ${ }^{29}$

In order to best evaluate and compare the three investigative analytical techniques used in this study, the images and results presented focus on the mesio-buccal area of the mid-section of the patient's tooth root. The inspection of the sample performed using optical microscopy showed that this is an intact area of the cross-section of the tooth and, therefore, represents the entire thickness of the AEFC formed throughout the life of this patient from the eruption to the moment of the extraction of this tooth. That is because the formation of the AEFC is a preprogramed process, and as long as the tissue is nutritionally supported by intact periodontal fibres, this mode of cementum formation continues throughout life. The AEFC will slowly increase in thickness, at a rate of about $1.5 \mu \mathrm{m}$ per year. ${ }^{1,3}$ Structural (incremental) lines within the tissue, seen in the cross-section, are indictors of the incremental nature of its formation. ${ }^{1}$ Because of this mode of AEFC formation, any metabolic disturbances during the life of an individual (e.g. pregnancies) affecting the mineralization of AEFC growth layers (i.e., incremental line/s) formed during respective period of life, should be recorded in the tissue itself and thus detectable in any intact area of cross-section of this tissue.

For comparison, the similar supporting results obtained by ToF-SIMS from the disto-buccal area of the tooth are given in $\mathrm{ESI} \dagger$ section of this paper.

\section{Study approval}

Use of human tissues and human sensitive data for this study was approved by the Ethics Committee of Faculty of Medicine, University of Pristina at Kosovska Mitrovica, Ministry of Health, Republic of Serbia, as well as by the Ethical Board of Research Executive Agency, European Commission, Brussels.

\section{Results and discussion}

\section{Light microscopy}

The quality of the incremental lines, more precisely, their visual effects were analysed from the microscopic images by the observers in the study (Fig. 1). Even though some appeared darker and/or wider than others, such lines were not visible throughout the whole tooth section, so manually counting lines

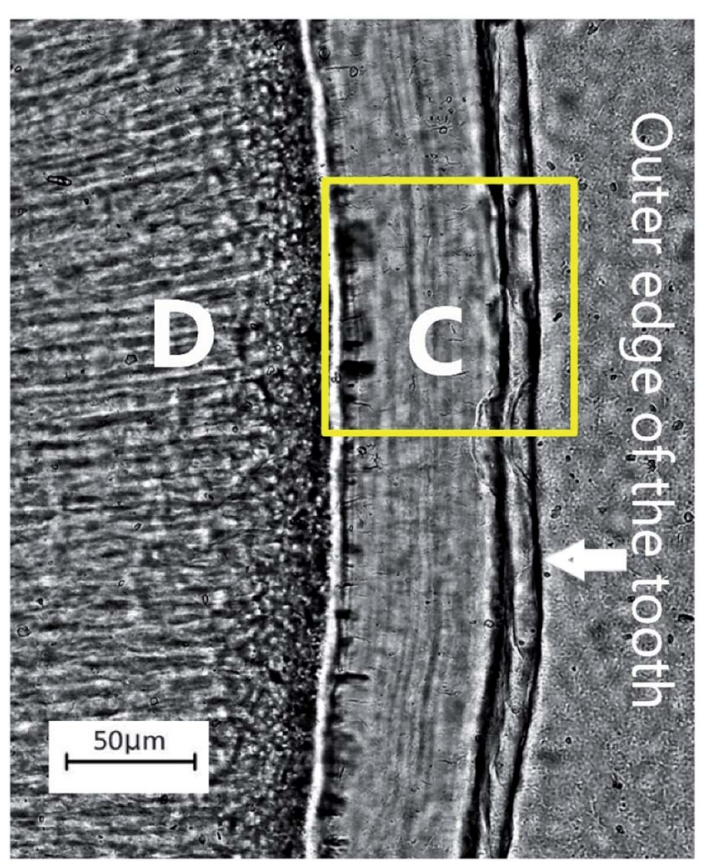

Fig. 1 The appearance of acellular extrinsic fibre cementum (AEFC) in a ground cross-section of the patient's tooth root under the transmitted polarized light microscope. C - AEFC; D - dentine; yellow square represents the location of the investigated areas by SEM-EDS and ToF-SIMS techniques (see Fig. 2 and 3). Note that for the SEM-EDS only the line scan was obtained across this area. 
in this manner may be considered, at best, a highly subjective process. Using transmitted polarized light microscopy, we demonstrated that the cross-section of the patient's AEFC contained incremental lines (Fig. 1). However, no observer could estimate accurate chronological age of this patient. Even when analysing segments of the cross-section with continuously visible incremental lines, the number of counted incremental lines by the observers in the study was inconsistent (Table 2). Hence, the estimated cementum age for the patient ranged between c. 30-65 years.

When observing the quality of incremental lines from these micro-images, we were not able to detect visually the patient's known series of six pregnancies which occurred within 10 years. While all of the observers in the study detected a number of incremental lines with different visual effects, so-called "crisislines", they have not appeared here as precisely datable events. That is, visually detected crisis lines in our sample did not match the age of the patient's pregnancies. In this instance, optical microscopy is of little use for understanding any structural and compositional characteristics of AEFC.

\section{SEM-EDS}

No visual evidence of cementum growth layering was found SEM micrograph using Philips XL30 FEG-SEM (Hillsboro, OR, USA) equipped with an Oxford instruments energy dispersive Xray analysis detector (Fig. 2a). The $\mathrm{Ca} / \mathrm{P}$ ratio (by atomic percent) ranged from 1.47 to 1.73 , with 1.59 as average value. Line scan for $\mathrm{Ca}$ showed no significant change in its relative amounts across the width of the cementum (Fig. 2b), except in the case of line spectrum (8) which exhibits the lowest relative amount of
$\mathrm{Ca}$ as of 0.13 (atomic\%), as well as the lowest $\mathrm{Ca} / \mathrm{P}$ ratio as of 1.29 by atomic\% (Fig. 2a). However, these low readings for the line spectrum (8) are due to an intruding artefact deposited in cementum, which can be clearly observed on electron photomicrograph of a transverse section of mid root cementum (Fig. 2a) and should not be taken into account when interpreting mineral distribution across the AEFC width of our sample.

\section{ToF-SIMS}

Layering of AEFC is somewhat visible from the ION-TOF.SIMS5 camera view (Fig. 3a), but not in a form of clearly defined incremental lines. On the other hand, we were able to attribute the distance in $\mu \mathrm{m}$ in the Fig. $3 \mathrm{~b}$ to a life period defined in calendar years of the patient, by calculating the approximal width of AEFC incremental lines from the micrograph shown in the Fig. 3a. Several studies have shown that the histological age of an individual can be estimated by adding the number of AEFC incremental lines to the year of eruption of the respective tooth. ${ }^{3,12,24}$ Furthermore, the fact that AEFC layers (incremental lines) are formed in a regular annual rhythm at rate of about 1.5 $\mu \mathrm{m}$ per year, ${ }^{1,3}$ enabled us to approximate the width of incremental lines using the total width of the intact cementum layer measured from the ToF-SIMS micrograph (Fig. 3a). As shown in Fig. 3a, the analysed AEFC is flanked by cemento-dentinal junction on one side and outer edge of the tooth on the other side. Therefore, the total width of AEFC in our sample equals 73 $\mu \mathrm{m}$, and it correlates to the distance between $4 \mu \mathrm{m}$ (the age of the eruption) and $77 \mu \mathrm{m}$ (the age of the extraction) on the linescans (Fig. 3b). Given the average sex specific year of eruption of the tooth, which is 9.6 for mandibular canines in females, ${ }^{\mathbf{3 0 , 3 1}}$ as
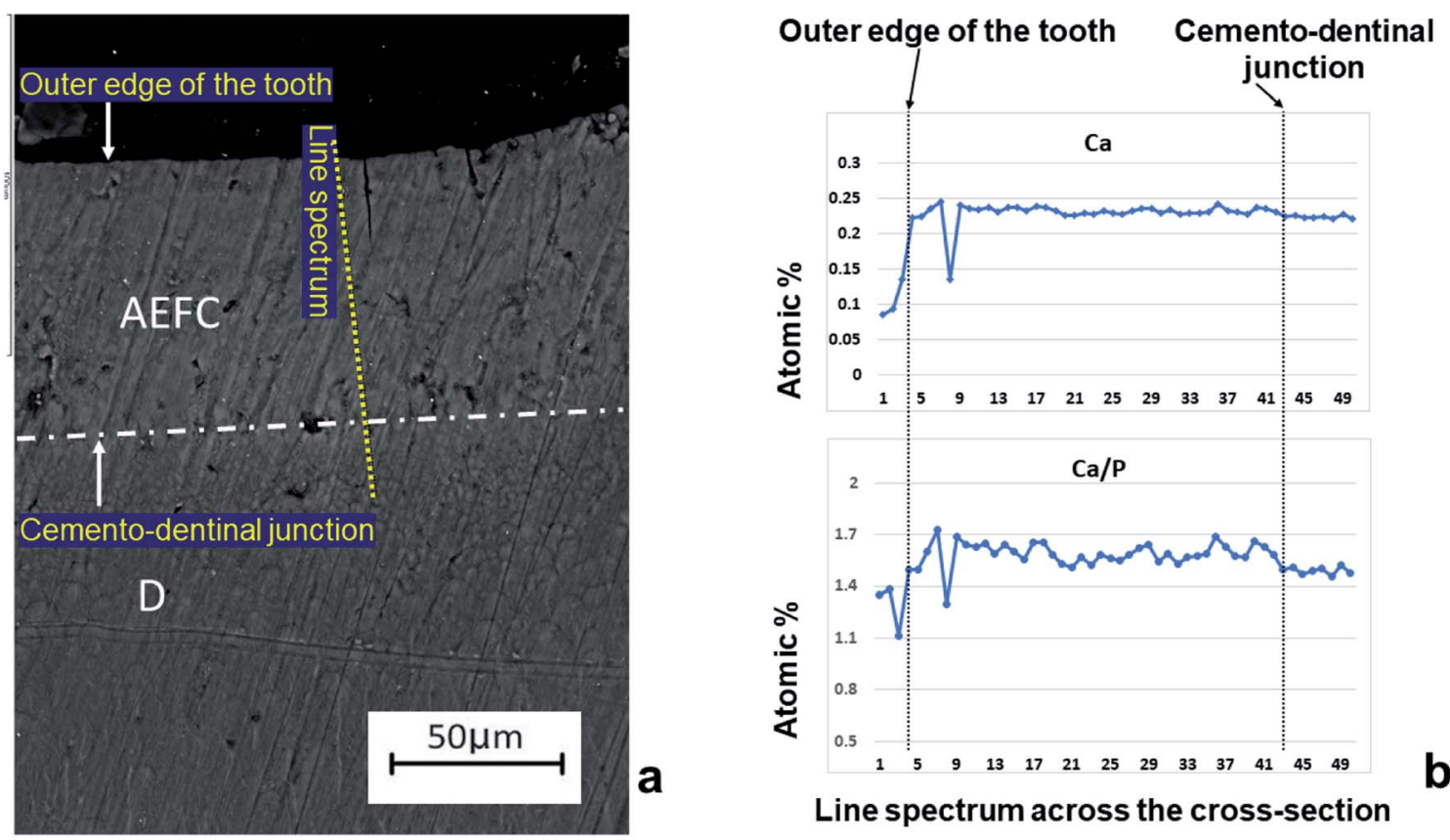

Line spectrum across the cross-section

Fig. 2 Results of EDS line analysis of the cross section of the patient's tooth. The SEM photomicrograph of the cross section (a) is showing the location across mid-root acellular extrinsic fiber cementum (AEFC) and dentine (D) where the line spectrum was taken. The line charts (b) represent results of EDS line scan analyses for $\mathrm{Ca}$ (upper chart) and $\mathrm{Ca} / \mathrm{P}$ ratio (lower chart) across the width of $\mathrm{AEFC}$. 
a

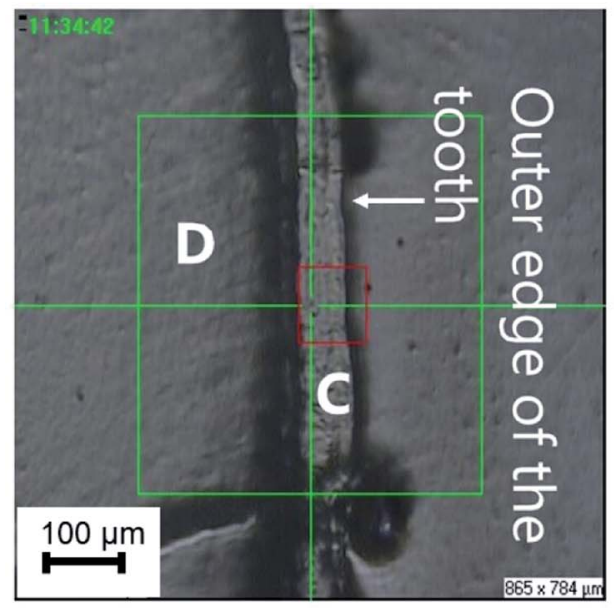

b

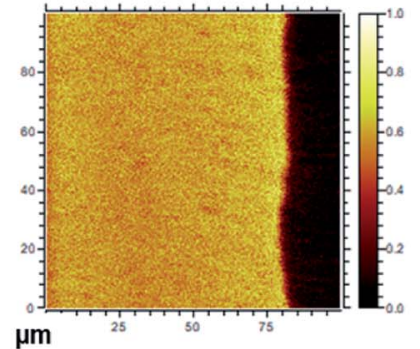

$\mathrm{Ca}+$ normalized to total

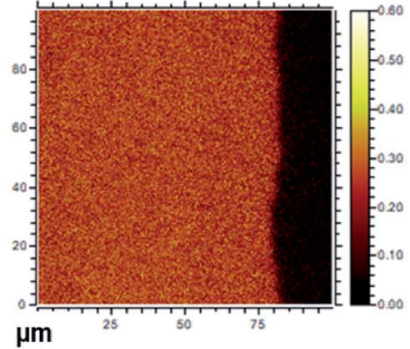

HAp+ normalized to total

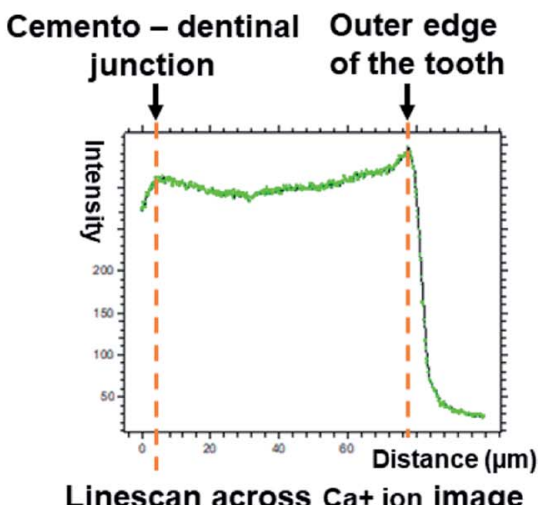

Linescan across $\mathrm{Ca}+$ ion image

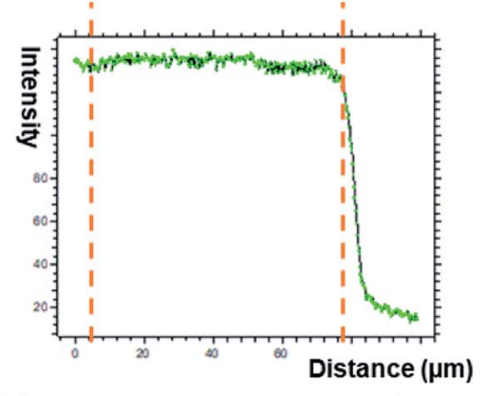

Linescan across HAp+ ion image

Fig. 3 Distribution of the molecular ions identified by SIMS in mesio-buccal area of the tooth. (a) A ToF-SIMS micrograph of the area of interest. "D" represents dentine; "C" represents acellular extrinsic fiber cementum; red square is demarking the area which has been analysed by ToFSIMS. (b) Molecular ion mapping and line scan ion images of calcium ( $\mathrm{Ca}+$ ), and hydroxyapatite (HAp+). The ion images are normalized to the total ion current.

well as the age of extraction for this tooth (66 years), the distance of $73 \mu \mathrm{m}$ (between $4-77 \mu \mathrm{m}$ on the linescans, Fig. 3b) corresponds to 56.4 years of life of the patient. By dividing the distance of $73 \mu \mathrm{m}$ by 56.4, we calculated that the width of an annually formed incremental line is approximately $1.3 \mu \mathrm{m}$ for this patient.

The elemental and molecular maps, as well as line scans of $\mathrm{Ca}+$ and $\mathrm{HAp}+(\mathrm{Ca} / \mathrm{P}$ ratio) are obtained from the AEFC surface. We have detected a variation in the intensity of $\mathrm{Ca}+$ across the analyzed AEFC surface (Fig. 3b). A depletion in relative $\mathrm{Ca}+$ intensity can be observed from $12-54 \mu \mathrm{m}$ respectively (Fig. $3 \mathrm{~b}$ and 4$)$. Based on calculated incremental line width $(1.3 \mu \mathrm{m})$, we can estimate that there is approximately nine incremental lines within $12 \mu \mathrm{m}$, and 41 lines within $54 \mu \mathrm{m}$ of the observed AEFC. By adding the number of incremental lines to the age of the eruption of the observed tooth (9.6 years), we can estimate the chronological span during the patient life when the cementum between $12-54 \mu \mathrm{m}$ is formed. This corresponds to approximately $19^{\text {th }}$ to $50^{\text {th }}$ year the patient's life (Fig. 4). The lowest point in Ca+ intensity depletion is recorded at $32^{\text {nd }} \mu \mathrm{m}$ (Fig. 4) which corresponds to middle of $4^{\text {th }}$ decade of the patient's life (approximately at the age of 34). On the other hand, as no depletion in intensity of $\mathrm{HAp}+$ was detected in the same line scan, we advise that these results are treated cautiously (Fig. 3b and 4).

This study compared the results of three different microscopic techniques in order to establish whether any can accurately estimate the degree and distribution of mineralisation of
AEFC. The results of the three methods were compared with the recorded life history parameters of an ideal subject who had six full-term pregnancies. Light microscopy results were ambiguous and should be treated with caution here. We then show how degree and distribution of mineralisation and connected life history parameter detection in AEFC varied between two elemental detection methods, SEM-EDS and ToF-SIMS.

Scanning electron microscope with electro-dispersive probe did not detect any significant variation in Ca relative amounts across the AEFC width, nor in $\mathrm{Ca} / \mathrm{P}$ ratio respectively (Fig. $2 \mathrm{~b}$ ). The range for the $\mathrm{Ca} / \mathrm{P}$ ratio (by atomic percent) varied between 1.47 to 1.73 , where the majority of the values (Fig. $2 \mathrm{~b}$ ) fell below 1.65 , and the value 1.73 was read only once. This implies that our results for $\mathrm{Ca} / \mathrm{P}$ atomic percent ratio are significantly lower than the $\mathrm{Ca} / \mathrm{P}$ atomic ratio bioapatite standard (1.69-1.71). These results suggest that the AEFC analysed here is relatively hypomineralised overall. The aim of this study was to detect variation in degree and distribution of mineralisation across the AEFC cross-section, therefore, it is of little use to discuss the average $\mathrm{Ca} / \mathrm{P}$ ratio we obtained. In terms of previous research that found no obvious variation in the concentration profile for calcium and phosphorus, our results are in general agreement. ${ }^{9}$ The authors of that study reported that calcium and phosphorus are present in cementum at a ratio (1.70) similar to the bioapatite standard, which disagrees with our results. They concluded that "cementum growth involves a constant rate of both mineralisation and matrix production, rather than 

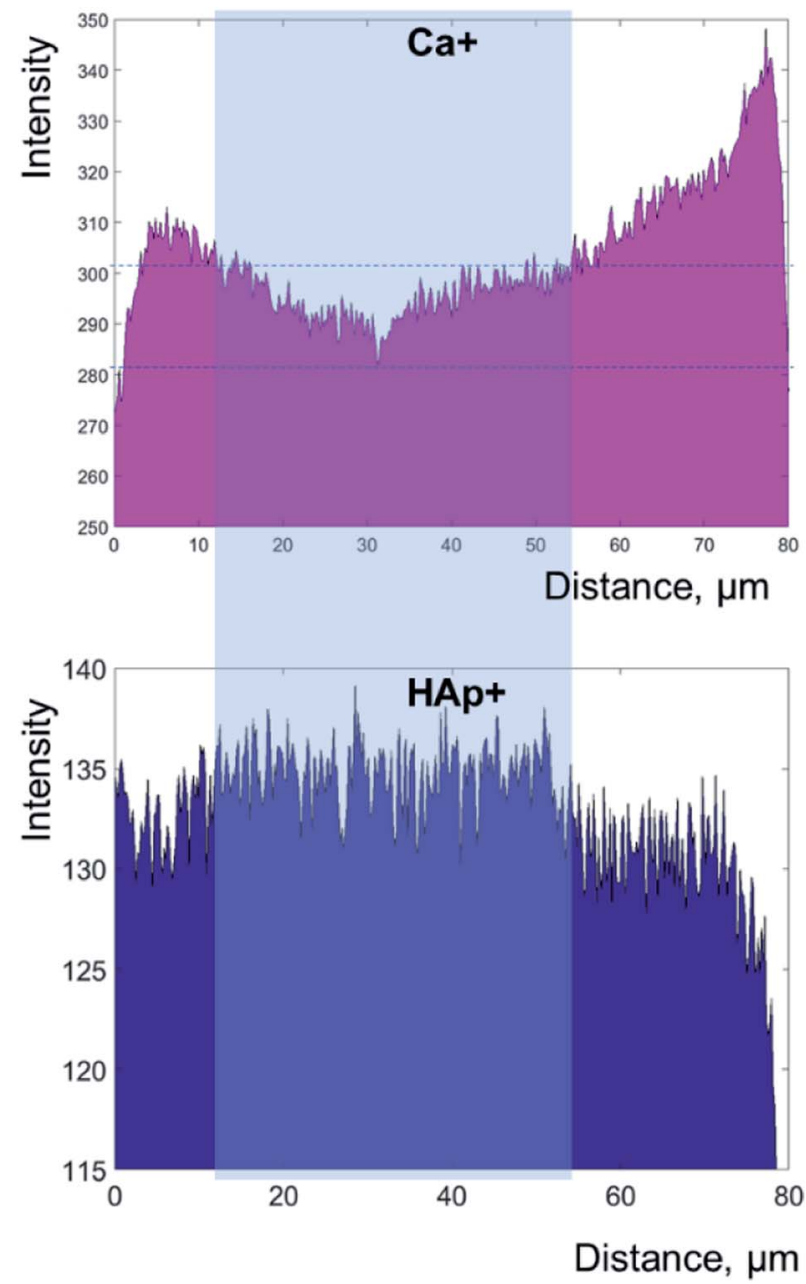

Fig. 4 Secondary ion yield (counts) of calcium ( $\mathrm{Ca}+$ ) and hydroxyapatite $(\mathrm{HAp}+)$ across the width of the cementum, both normalized to total ion current. The data plotted as histograms in this figure for more clarity are obtained by ToF-SIMS analysis represented as linescans in Fig. 3b. Right side of the plots represents outer edge of the tooth.

variations in the rate of matrix production with mineralisation continuing at a uniform rate", ${ }^{9}$ which is opposite of what was reported in Lieberman's work. ${ }^{32}$ Apart from stating that the cross-section was taken through areas shown to contain growth layers, the authors ${ }^{9}$ had not specified precisely which type of cementum they analyzed in their study. This implies that they were observing cementum as a single uniform type of tissue. A similar approach was taken in a few previous studies when analyzing cementum with electron probes. ${ }^{33,34}$ Importantly, there are various types of cementum which must be distinctly classified based on presence or absence of cells, nature and origin of organic matrix, or a combination of these factors. ${ }^{1,35,36}$ Different types of cementum are formed at different rates, but only AEFC is considered annually deposited. Most importantly, incremental lines are found in different types of cementum (e.g. in acellular and cellular cementum). Furthermore, EDS analysis can only be used to obtain the relative amounts of concretions even when certified standards are used; as EDS operating software does not provide us with continuous elemental values.
This might be the reason we were not able to detect any obvious variation in $\mathrm{Ca}$ and $\mathrm{P}$ profiles. With all this in mind, we argue that the SEM-EDS technique is inadequate tool for measuring either degree or distribution of AEFC mineralisation.

On the other hand, ToF-SIMS micro-imaging revealed clearly defined AEFC in our cross-section. Although some appearance of layering within AEFC can be also observed (Fig. 3a), the incremental lines of AEFC were not clearly discernible from the micrograph. On the other hand, we were able to estimate the approximate width of AEFC incremental lines using the micrograph itself. The linescans showed obvious variation in Ca+ intensity across the AEFC width, but not for HAp+ (Fig. 3b and 4). Ca+ intensity variation has been detected in a form of a depletion which might correlate with the with patient's pregnancies, as the depletion of $\mathrm{Ca}+$ intensity corresponds to the patient's $2^{\text {nd }}$ to $5^{\text {th }}$ life decade (Fig. 4). The initial Ca+ intensity depletion in the AEFC of the patient's tooth matches the exact age of her first pregnancy. The lowest point in $\mathrm{Ca}+$ intensity depletion is recorded at $32^{\text {nd }} \mu \mathrm{m}$ which corresponds to the middle of the patent's $4^{\text {th }}$ life decade, just after the age of her last pregnancy. From that point on, the intensity values for $\mathrm{Ca}+$ are seen to rise, or perhaps normalise, after final pregnancy.

\section{Conclusions}

In summary, our results challenge an established reliance on optical microscopy when identifying life history parameters on the basis of incremental lines' visual effects. We have also demonstrated how use of the SEM-EDS technique alone is inadequate for measuring degree and distribution of AEFC mineralisation at around $1 \mu \mathrm{m}$ resolution. On the other hand, our ToF-SIMS results strongly suggest that life history parameters, such as pregnancies, are more likely to influence AEFC in terms of relatively reduced mineralisation, which is in accordance with work done by Kagerer and Grupe. ${ }^{3}$ Thus, to detect life history parameters that have a marked impact on $\mathrm{Ca}$ metabolism, such as pregnancies, we recommend use of Timeof-Flight Secondary Ion Mass Spectrometry, as we observe a clear relationship between degree and distribution of AEFC mineralisation and reported pregnancies. Even though ToFSIMS results presented here are qualitative, this technique has great potential for human life history research using records of cementum growth. This study can serve as a benchmark for further ToF-SIMS analyses examining the relationship between degree and distribution of the AEFC mineralisation and reported life history parameters such as pregnancies. There is clearly good reason to extend the scope of this research in the future with more samples using ToF-SIMS, allowing for depth profiles and 3D analyses that may clarify our initial findings. Nonetheless, there are several limitations to be aware of when using ToF-SIMS in cementum mineralization studies. While there is apparently a relationship between mineralization of the AEFC and pregnancies, it was not possible to separate oscillations in AEFC mineral density precisely to an annual resolution that coincided with the annual timing of known pregnancies in our subject. Another limitation of the study may result from 
matrix effect, but we have taken many precautionary steps to account for this issue, from appropriate sample preparation procedures, through to suitable choice of the analytical equipment setup. To avoid over-interpretation of data obtained by optical or SEM analyses from AEFC samples, we urge similar cautionary measures be exercised by other researchers in this field.

\section{Conflicts of interest}

There are no conflicts to declare.

\section{Acknowledgements}

The authors thank Stepan Shennan and Eric Reynolds for providing useful comments on earlier versions of the paper. They also thank Bisa Radović and Božidar Milošević for enabling the research collaboration with the University of Priština. Analysis of dental samples was carried out in the framework of the European Union's Horizon 2020 research and innovation programme under the Marie Sklodowska-Curie actions, project EUROLIFE (grant agreement No. 656203) awarded to M. E.

\section{References}

1 B. G. Berkovitz, G. Holland and B. Moxham, Oral Anatomy, Histology and Embryology, Elsevier Limited, Beijing, 4th edn, 2009.

2 D. E. Lieberman, Life history variables preserved in dental cementum microstructure, Science, 1993, 261, 1162-1164, DOI: $10.1126 /$ science.8356448.

3 P. Kagerer and G. Grupe, Age-at-death diagnosis and determination of life-history parameters by incremental lines in human dental cementum as an identification aid, Forensic Sci. Int., 2001, 118, 75-82.

4 U. Wittwer-Backofen, J. Gampe and J. W. Vaupel, Tooth cementum annulation for age estimation: Results from a large known-age validation study, Am. J. Phys. Anthropol., 2004, 123(2), 119-129.

5 S. Naji, T. Colard, J. Blondiaux, B. Bertrand, E. d'Incau and J. Bocquet-Appel, Cementochronology, to cut or not to cut?, Int. J. Paleopathol., 2016, 15, 113-119, DOI: 10.1016/ j.ijpp.2014.05.003.

6 C. S. Kovacs and H. M. Kroneneberg, Maternal-fetal calcium and bone metabolism during pregnancy, puerperium, and lactation, Endocr. Rev., 1997, 18(6), 832-872.

7 S. Harada and G. A. Rodan, Control of osteoblast function and regulation of bone mass, Nature, 2003, 423, 349-355.

8 A. Cipriano, Cold stress in captive great apes recorded in incremental lines of dental cementum, Folia Primatol., 2002, 73, 21-31.

9 S. M. Cool, M. R. Forwood, P. Campbell and M. B. Bennett, Comparisons between bone and cementum compositions and the possible basis for their layered appearances, Bone, 2002, 30(2), 386-392.
10 T. Colard, G. Falgayrac, B. Bertrand, S. Naji, O. Devos, C. Balsack, et al., New Insights on the Composition and the Structure of the Acellular Extrinsic Fiber Cementum by Raman Analysis, PLoS One, 2016, 11(12), e0167316, DOI: 10.1371/journal.pone.0167316.

11 R. M. Laws, A new method of age determination for mammals, Nature, 1952, 169, 972-973.

12 G. G. Stott, R. F. Sis and B. M. Levy, Cemental annulation as an age criterion in forensic dentistry, J. Dent. Res., 1982, 61, 814-817.

13 D. E. Lieberman and R. H. Meadow, The biology of cementum increments (with an archaeological application), Mammal Rev., 1992, 22(2), 57-77.

14 U. Wittwer-Backofen and H. Buba, in Paleodemography: Age Distributions from Skeletal Samples Age Estimation by Tooth Cementum Annulations, ed. R. D. Hoppa and J. W. Vaupel, Cambridge University Press, Cambridge, 2002, pp. 107-128.

15 R. Bojarun, A. Garmus and R. Jankauskas, Microstructure of dental cementum and individual biological age estimation, Medicina, 2003, 39(10), 960-964.

16 A. Lippitsch and G. Grupe, in Skeletal Series and Their SocioEconomic Context: Variability of the apposition of the acellular, extrinsic fiber cementum and its influence on the tooth cementum annulation technique in humans: the influence of physical demands and functional morphology, ed. G. Grupe and J. Peters, M. Leidorf, Rahden/Westf., 2007, pp. 87-112.

17 P. E. Dias, T. L. Beaini and R. F. Melani, Age estimation from dental cementum incremental lines and periodontal disease, J. Forensic Odontostomatol., 2010, 28, 13-21.

18 S. Kasetty, M. Rammanohar and T. Raju Ragavendra, Dental cementum in age estimation: a polarized light and stereomicroscopic study, J. Forensic Sci., 2010, 55, 779-783.

19 M. B. Radović, Ageing in the Danube Gorges population (9500-5500 BC) - Tooth Cementum Annulation method, Starinar, 2012, 42, 9-18, DOI: 10.2298/STA1262009R.

20 G. R. Schug, E. T. Brandt and J. R. Lukacs, Cementum annulations, age estimation, and demographic dynamics in Mid-Holocene foragers of North India, HOMO - Journal of Comparative Human Biology, 2012, 63(2), 94-109.

$21 \mathrm{~J}$. Gauthier and H. Schutkowski, Assessing the application of tooth cementum annulation relative to macroscopic aging techniques in an archeological sample, HOMO, 2013, 64, 42-57, DOI: 10.1016/j.jchb.2012.11.001.

22 B. Bertrand, S. G. Robbins, C. Polet, S. Naji and T. Colard, Age-at-death estimation of pathological individuals: a complementary approach using teeth cementum annulations, Int. J. Paleopathol., 2016, 15, 120-127, DOI: 10.1016/j.ijpp.2014.04.001.

23 F. E. Lipsinic, E. Paunovich, G. D. Houston and S. F. Robison, Correlation of age and incremental lines in the cementum of human teeth, J. Forensic Sci., 1986, 31(3), 982-989.

24 H. Renz and R. J. Radlanski, Incremental Lines in Root Cementum of Human Teeth - A Reliable Age Marker?, HOMO - Journal of Comparative Human Biology, 2006, 57(1), 29-50, DOI: 10.1016/j.jchb.2005.09.002. 
25 A. Le Cabec, N. K. Tang, V. Ruano Rubio and S. Hillson, Nondestructive adult age at death estimation: Visualizing cementum annulations in a known age historical human assemblage using synchrotron X-ray microtomography, Am. J. Phys. Anthropol., 2019, 168, 25-44.

26 M. M. Ristova and Z. Stojanovska, Accurate Age Estimations from Dental Cementum and a Childbirth Indicator - a Pilot Study, Journal of Forensic Science \& Criminology, 2018, 6(1), 102.

27 H. Tellez, A. Aguadero, J. Druce, M. Burriel, S. Fearn, T. Ishihara, D. S. McPhail and J. A. Kilner, New perspectives in the surface analysis of energy materials by combined time-of-flight secondary ion mass spectrometry (ToF-SIMS) and high sensitivity low-energy ion scattering (HS-LEIS), J. Anal. At. Spectrom., 2014, 29, 1361-1370.

28 A. Torrisi, V. Torrisi, N. Tuccitto, M. G. Gandolfi, C. Prati and A. Licciardello, ToF-SIMS images and spectra of biomimetic calcium silicate-based cements after storage in solutions simulating the effects of human biological fluids, Int. J. Mass Spectrom., 2010, 289, 150-161.

29 J. L. Norris, D. S. Cornett, J. A. Mobley, M. Andersson, E. H. Seeley, P. Chaurand and R. M. Caprioli, Processing MALDI mass spectra to improve mass spectral direct tissue analysis, Int. J. Mass Spectrom., 2007, 260(2-3), 212-221, DOI: $10.1016 /$ j.ijms.2006.10.005.
$30 \mathrm{~S}$. Helm and B. Seidler, Timing of permanent tooth emergence in Danish children, Community Dentistry and Oral Epidemiology, 1974, 2, 122-129, DOI: 10.1111/j.16000528.1974.tb01669.x.

31 S. J. Nelson and M. M. Ash, Wheeler's Dental Anatomy, Physiology, and Occlusion, Saunders Elsevier, St. Louis, Mo., 9th edn, 2009.

32 D. E. Lieberman, The biological basis of seasonal increments in dental cementum and their application to archaeological research, J. Archaeol. Sci., 1994, 21, 525-539.

33 E. Hals and K. A. Selvig, Correlated electron probe microanalysis and microradiography of carious and normal dental cementum, Caries Res., 1977, 11, 62-75.

34 K. A. Selvig and E. Hals, Periodontally diseased cementum studied by correlated microradiography, electron probe analysis and electron microscopy, J. Periodontal Res., 1977, 12, 419-429.

35 H. Yamamoto, T. Niimi, R. Yokota-Ohta, K. Suzuki, T. Sakae and Y. Kozawa Y, Diversity of Acellular and Cellular Cementum Distribution in Human Permanent Teeth, $J$. Hard Tissue Biol., 2009, 18(1), 40-44.

36 S. P. Ho, S. J. Marshall, M. I. Ryder and G. W. Marshall, The tooth attachment mechanism defined by structure, chemical composition and mechanical properties of collagen fibers in the periodontium, Biomaterials, 2007, 28(35), 5238-5245, DOI: 10.1016/j.biomaterials.2007.08.031. 